\title{
Sterols, Steroidal Sapogenin and Steroidal Alkaloid in Callus Culture of Solanum laciniatum Ait.
}

\author{
Noriyo Hosoda and Michihiko Yatazawa \\ Faculty of Agriculture, Nagoya University, Chikusa, Nagoya, Japan \\ Received November 27, 1978
}

\begin{abstract}
Aiming to get useful steroidal alkaloids by tissue culture of Solanum laciniatum Ait., indefinitely growing callus tissue was prepared from the mother plant. Some nutritional requirements for the growth of the callus tissue were studied. By examining steroidal compounds in callus culture, cholesterol, stigmasterol, $\beta$-sitosterol, lanosterol, squalene, diosgenin and a new steroidal alkaloid were found to be formed in the callus culture. The new steroidal alkaloid was found to be solasodine derivative containing rhamnose and other unidentified sugars.
\end{abstract}

Solanum laciniatum Ait. is commercially cultivated in tropical countries especially in India, Australia, New Zealand, and Egypt for producing a steroidal alkaloid solasodine, because solasodine is a starting material for synthesizing various kinds of steroidal hormones. In $S$. laciniatum Ait. especially in young fruits, there exist several kinds of steroidal alkaloids and steroidal sapogenins. ${ }^{1 \sim 3)}$ They include solasonine, solamargine, $\beta$ solamargine, chlorogenin, and diosgenin. Some other species of Solanum genus also contain similar steroidal alkaloids. Therefore several attempts have been made to produce diosgenin in tissue culture of Solanum plant species. ${ }^{4 \sim 10}$ But satisfactory results have not yet been obtained. With $S$. laciniatum Ait., Rérábek reported that 2, 4-D and myo-inositol were effective in the formation of callus from excised roots of the plant. ${ }^{11}$ Vágújfalvi et al., revealed several years ago that tissue culture of $S$. laciniatum Ait. contained a trace amount of diosgenin, but didn't produce solasodine. ${ }^{12}$,

In the course of our study to get steroidal alkaloid by tissue culture of $S$. laciniatum Ait., some informations about the presence of steroidal compounds in callus culture of the plant were obtained. This paper reports some nutritional requirments for the growth of callus tissue of $S$. laciniatum Ait. and the formation of sterols, steroidal sapogenin and a new steroi- dal alkaloid in the callus culture.

\section{MATERIALS AND METHODS}

Callus tissue. Seeds of Solanum laciniatum Ait. were obtained by the courtesy of Izu Experiment Station of Medicinal Plants, National Institute of Hygienic Sciences. They were sterilized for $30 \mathrm{~min}$ in a $10 \%$ bleaching powder aqueous solution, washed thoroughly with sterile distilled water and germinated on $0.9 \%$ agar medium containing Murashige-Skoog's mineral nutrients ${ }^{13)}$ at $25^{\circ} \mathrm{C}$ in the dark. Germinated seedlings were placed on a modified Murashige-Skoog's tobacco medium $^{13)}$ supplemented with yeast extract $(1 \mathrm{~g} /$ liter $)$ and 2, 4-D $(1 \mathrm{ml} /$ liter $)$ otherwise indicated in the text. This medium was designated as PN (Table I). Generated callus tissues were subcultured repeatedly with PN medium.

Culture method. To examine the effect of 2, 4-D, kinetin, casein hydrolysate, or yeast extract on the growth of callus tissue, small pieces of subcultured tissues were placed on a solid PN medium containing varied amount of test substances, and incubated for 3 weeks at $25^{\circ} \mathrm{C}$ in the dark otherwise indicated in the text. After harvest fresh weight and dry weight were measured.

Cultures to be used for analyzing chemical metabolites were made by the similar way as of subculture conditions.

\section{Chemical analysis.}

Extraction. About $500 \mathrm{~g}$ of fresh root callus tissue was homogenized in cold acetone with a little sea sand and allowed to satnd for 7 days. Insoluble material in the homogenate was removed by filtration and the 
Table I, Composition of PN Medium for the Tissue Culture

\begin{tabular}{lccc}
\multicolumn{1}{c}{ Compound } & $\mathrm{mg} /$ liter & \multicolumn{1}{c}{ Compound } & mg/liter \\
\hline $\mathrm{NH}_{4} \mathrm{NO}_{3}$ & 1650 & Thiamine $\cdot \mathrm{HCl}$ & 0.5 \\
$\mathrm{KNO}_{3}$ & 1900 & Pyridoxine $\cdot \mathrm{HCl}$ & 0.5 \\
$\mathrm{CaCl}_{2} \cdot 2 \mathrm{H}_{2} \mathrm{O}$ & 440 & Nicotinic Acid & 0.5 \\
$\mathrm{MgSO}_{4} \cdot 7 \mathrm{H}_{2} \mathrm{O}$ & 370 & Myo-insositol & 100 \\
$\mathrm{KH}_{2} \mathrm{PO}_{4}$ & 170 & $2,4-\mathrm{D}$ & 1 \\
$\mathrm{Na}_{2} \mathrm{EDTA}$ & 37.3 & Dried Yeast Ext. & 1000 \\
$\mathrm{FeSO}_{4} \cdot 7 \mathrm{H}_{2} \mathrm{O}$ & 27.8 & Sucrose & 20000 \\
$\mathrm{H}_{3} \mathrm{BO}_{3}$ & 6.2 & Agar & 9000 \\
$\mathrm{MnSO}_{4} \cdot 4 \mathrm{H}_{2} \mathrm{O}$ & 22.3 & & \\
$\mathrm{ZnSO}_{4} \cdot 4 \mathrm{H}_{2} \mathrm{O}$ & 8.6 & & \\
$\mathrm{KI}_{\mathrm{Na}_{2} \mathrm{MoO}_{4} \cdot 2 \mathrm{H}_{2} \mathrm{O}}$ & 0.83 & & \\
$\mathrm{CuSO}_{4} \cdot 5 \mathrm{H}_{2} \mathrm{O}$ & 0.25 & & \\
$\mathrm{CoCl}_{2} \cdot 6 \mathrm{H}_{2} \mathrm{O}$ & 0.025 & & \\
\hline
\end{tabular}

The $\mathrm{pH}$ of the medium was adjusted to 6.0 with $1 \mathrm{~N}-\mathrm{NaOH}$.

filtrate, after acidification with $10 \%$ acetic acid, was concentrated to small volume under reduced pressure below $40^{\circ} \mathrm{C}$. The concentrated solution was extracted twice with methylene chloride. The methylene chloride solution was dried over anhydrous sodium sulfate and evaporated to dryness. The residue was designated as Fraction A. The aqueous solution ( $\mathrm{pH} 3.2$ ) of the residue was made alkaline ( $\mathrm{pH} 10$ ) by an addition of $28 \% \mathrm{NH}_{4} \mathrm{OH}$ and re-extracted into methylene chloride. The methylene chloride solution was dried over anhydrous sodium sulfate and evaporated to dryness. The residue was designated as Fraction B. Each Fraction $\mathbf{A}$ and $\mathbf{B}$ was dissolved in a small amount of acetone and submitted to thin-layer chromatography. Fraction $\mathrm{A}$ was also analyzed by gas-liquid chromatography.

Hydrolysis of Fraction B. Fraction B dissolved in a small amount of ethanol was hydrolyzed with conc. $\mathrm{HCl}$ by refluxing for $3 \mathrm{hr} .^{1)}$ A part of hydrolysate was treated with $\mathrm{NH}_{4} \mathrm{OH}$ to isolate aglycone. The aglycone was analyzed by TLC. The remaining hydrolysate was used for an examination of sugars.

Thin-layer chromatography. Fraction A containing sterols was analyzed on a TLC-plate of $0.25 \mathrm{~mm}$ thickness of Kieselguhr $\mathrm{G}$ (Merck) using solvent system benzene-ethyl ether $(8: 2)$ or benzene-ethyl acetate $(3: 1)$. The spots were detected by spraying anisaldehyde reagent followed by heating to $100^{\circ} \mathrm{C}$ for $10 \mathrm{~min}$, spraying conc. $\mathrm{H}_{2} \mathrm{SO}_{4}$ or $20 \%$ antimony trichloride in chloroform followed by heating for 5 min. Fraction $B$ which contained alkaloids was analyzed on TLC employing several solvent systems as described in Table II and Dragendorff's spraying reagent.

Aglycones were examined on TLC using chloroformmethanol or benzene-methanol and $20 \%$ antimony trichloride in chloroform as a spraying reagent.

Sugars in hydrolysate were concentrated and applied on TLC of Kieselguhr G with sodium acetate. Ethyl

Table II. Rf-Values of Basic Fraction Using Thin-Layer Chromatography on Silicagel G in Various Solvent Systems and with Dragendorff's Reagent as Spraying ReAgent

\begin{tabular}{|c|c|c|c|c|}
\hline \multirow{2}{*}{\multicolumn{2}{|c|}{ Solvent systems }} & \multicolumn{3}{|c|}{ Rf-Values } \\
\hline & & Solasonine & Solamargine & Fraction $\mathrm{B}$ \\
\hline Butanol-acetic acid-water & $(4: 1: 1)$ & 0.43 & 0.61 & 0.61 \\
\hline Butanol-acetic acid-water & $(4: 0.5: 0.5)$ & 0.24 & 0.48 & 0.55 \\
\hline Butanol-ethanol-water & (5:1:4 upper) & 0.32 & 0.47 & 0.71 \\
\hline \multicolumn{5}{|c|}{ Chloroform-methanol-ammonia water } \\
\hline \multicolumn{4}{|c|}{ Chloroform-ethanol- $1 \%$ ammonia water } & 0.84 \\
\hline \multicolumn{5}{|c|}{ Ethyl acetate-pyridine-water } \\
\hline & (3:1:3 upper) & 0.31 & 0.58 & 0.75 \\
\hline
\end{tabular}


acetate-mixture of 2 volumes of isopropanol and 1 volume of water (65: 35 ) was used as a solvent system and anisaldehyde- $\mathrm{H}_{2} \mathrm{SO}_{4}$ as a spraying reagent. ${ }^{14)}$

Gas-liquid chromatography. A Shimadzu Model GC-4A (PFE) gas chromatograph equipped with a hydrogen flame ionization detector and glass column $(4 \mathrm{~mm} \times 2 \mathrm{~m})$ packed with $1.5 \% \mathrm{OV}-17$ on Shimalite W (80 100 mesh) was used. Operation was conducted under conditions of nitrogen flow rate at $55 \mathrm{ml} / \mathrm{min}$, column temperature at $260^{\circ} \mathrm{C}$, flash heater temperature at $300^{\circ} \mathrm{C}$ and detector temperature at $290^{\circ} \mathrm{C}$.

\section{RESULTS AND DISCUSSION}

\section{Induction and growth of callus tissues}

Callus tissue was easily induced and proliferated vigorously on PN medium. When kinetin was added to PN medium at $0.1 \mathrm{ppm}$, induction of callus tissues became worse. Callus tissues grew well in both light and dark. The tissues subcultured in the dark became pale and soft, while the tissues subcultured in the light became hard and in part greenish pigmented.

PN medium contains 1 ppm 2, 4-D. Therefore the effect of 2,4-D concentration on the growth of callus tissues was examined at $0 \sim$ $10 \mathrm{ppm}$. The result revealed that optimum concentration of 2,4-D was $0.5 \mathrm{ppm}$ and at less than $0.1 \mathrm{ppm}$ or at more than $5 \mathrm{ppm}$ of 2, 4-D, the growth of callus tissue decreased greatly. According to Rao et al.," callus tissue of Solanum xanthocarpum generated roots and shoots when the callus tissue was cultured at low level of 2, 4-D. In our experiment no sign of differentiation was observed at nearly the same condition.

Effect of kinetin on the growth of callus tissue was also examined by supplementing kinetin to PN medium at $0 \sim 1$ ppm concentrations. The result revealed that any supplementation of kinetin was harmful for the growth of callus tissue. But no organogenesis or differentiation of the callus tissue was observed.

No beneficial effect of casein hydrolysate on the growth of callus tissue was ascertained when supplemented at $0.05 \sim 1 \%$ concentra- tion.

On the other hand yeast extract was revealed to be most beneficial at $0.05 \sim 0.1 \%$ on the growth of the callus tissue.

\section{Sterols and alkaloid in the callus tissues}

TLC examination of Fraction A with the solvent system of benzene-ethyl ether $(8: 2)$ revealed the presence of a blue-purple spot (Rf 0.35 ) corresponding to the spot either of authentic stigmasterol, $\beta$-sitosterol or cholesterol and a purple spot ( $R f 0.52)$ corresponding to lanosterol $(R f 0.53)$ by spraying anisaldehyde reagent. Essentially the same result was obtained by spraying conc. $\mathrm{H}_{2} \mathrm{SO}_{4}$. By spraying antimony trichloride reagent, purple $(R f$ 0.35 ) and brown-purple ( $R f 0.52$ ) spots corresponding to the authentic sterols were developed. The same result was obtained in TLC using benzene-ethyl acetate (3:1) solvent system.

Ambiguous two spots seemingly corresponding to squalene and diosgenin were also observed.

GLC of Fraction A showed the presence of peaks each representing retention time coincident with standard squalene, cholesterol, stigmasterol and $\beta$-sitosterol respectively (Fig. 1). A peak corresponding to lanosterol was not observed in GLC. Other unidentified peak which seemingly corresponds to campesterol was also observed.

TLC of Fraction B was performed with a standard basic fraction prepared from mother plant. The basic fraction of the mother plant has been known to contain only two kinds of alkaloids solasonine and solamargine. Employing several solvent systems for TLC of Fraction $\mathrm{B}$, only one spot having orange color, more redish than the standards, was obtained. $R f$ value of this spot did not coincide with any one of solasonine or solamargine (Table II).

TLC of aglycone in hydrolysate of Fraction B (Table III) developed by chloroformmethanol (19:1) solvent system and antimony trichloride revealed the red-purple spot of $R f$ 0.28 (corresponding to solasodine. In TLC of benzene--methanol $(5: 1)$ solvent system, $R f$ 


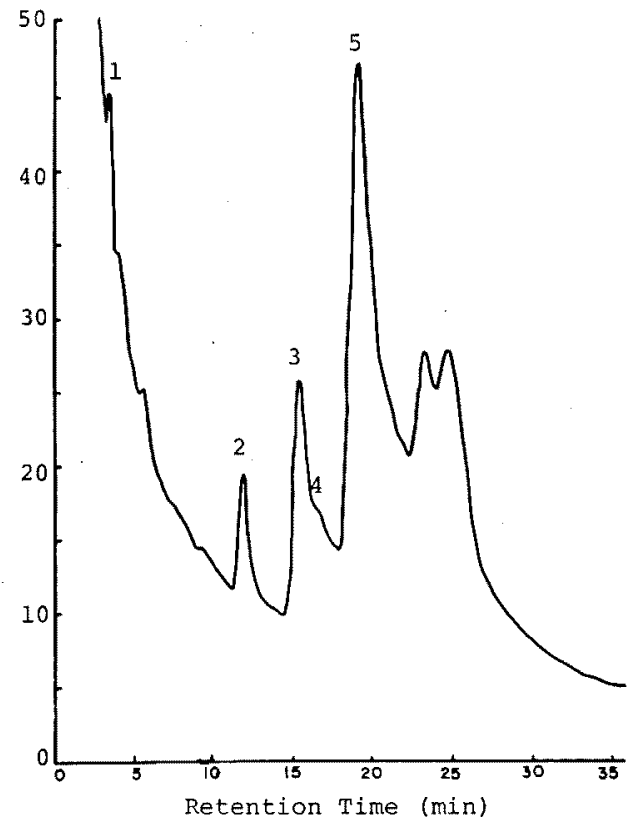

Frg. 1. Gas-liquid Chromatogram of Sterols from the Callus Tissue of Solanum laciniatum Ait.

1, Squalene; 2, cholesterol; 3, (campesterol); 4, stigmasterol; $5, \beta$-sitosterol.

values of hydrolysate aglycone and solasodine were 0.49 and 0.45 respectively. The presence of solasodine in the Fraction B hydrolysate was strongly suggested.

TLC examination of sugars in the concentrated hydrolysate of Fraction B showed 3 spots of $R f$ values of 0.23 (purple), 0.37 (grayblue) and 0.84 (yellow-green) (Table IV). The last spot was estimated to be rhamnose ( $R f$ 0.83 , green) whereas the others were not identified.

These results indicate that the callus tissues of S. laciniatum Ait. surely produced sterols, sapogenins and glycoalkaloid under the experimental conditions. The glycoalkaloid was revealed not to be solasonine or solamargine which are found in the mother plants. This alkaloid is composed of a common aglycone solasodine and several kinds of sugars. In addition high $R f$ value of this alkaloid in TLC suggest the number of composing sugars in the new glycoalkaloid would not be larger than that of solasonine or solamargine if the hydrolytic detachment of sugars didn't occur during
Table III. $R f$-Values of Steroidal Aglycone in Hydrolysate of Fraction B and Authentic Solasodine Using Thin-Layer Chromatography on Silicagel $\mathrm{G}$ and $20 \%$ ANTIMONY TRICHLORIDE IN CHLOROFORM as Spraying Reagent

\begin{tabular}{ccc}
\hline \multirow{2}{*}{ Solvent systems } & \multicolumn{2}{c}{$R f$-Values } \\
\cline { 2 - 3 } & Hydrolysate & Solasodine \\
\hline $\begin{array}{c}\text { Chloroform-methanol } \\
(19: 1)\end{array}$ & 0.28 & 0.29 \\
$\begin{array}{c}\text { Benzene-methanol } \\
(5: 1)\end{array}$ & 0.45 & 0.49 \\
\hline
\end{tabular}

Table IV. $R f$-Values of Sugars in Hydrolysate of Fraction B and Authentic Glucose, Galactose and Rhamnose Using Thin-LAyer Chromatography on Kieselguhr G WITH SODIUM ACETATE AND WITH ANISALDEHYDE- $\mathrm{H}_{2} \mathrm{SO}_{4}$ AS SPRAYING REAGENT

\begin{tabular}{cccc}
\hline Hydrolysate & Glucose & Galactose & Rhamnose \\
\hline 0.23 & & & \\
0.37 & 0.14 & 0.11 & 0.83 \\
0.84 & & & \\
\hline
\end{tabular}

the extraction procedure.

In conclusion, the callus culture of Solanum laciniatum Ait. certainly produce various kinds of steroidal compounds, cholesterol, $\beta$-sitosterol, lanosterol, stigmasterol, squalene, diosgenin, and a new steroidal alkaloid.

Acknowledgment. This study was supported in part by a grant from the Ministry of Education (Japan). The authors wish to acknowledge Dr. Y. Miyazaki, Izu Experiment Station of Medicinal Plants, for his kind supplying the seeds of Solanum laciniatum Ait. and Dr. M. Tabata, Kyoto University, for his kind suggestions. The authors also would like to thank Mr. N. Kurihara for his help in a part of this work.

\section{REFERENCES}

1) L. H. Briggs and R. C. Cambie, J. Chem. Soc., $1958,1422$.

2) A. R. Guseva, V. A. Pawashnichenko, M. G. Borikhina and P. K. Moiseev, Biokimiya, 30, 260 (1965).

3) A. A. Saleh, Planta Med., 26, 40 (1974).

4) P. S. Rao and S. Narayanaswami, Planta, 81, 372 (1968).

5) M. R. Heble, S. Narayanaswami and M.S. 
Chadha, Naturwissenschaften, 55, 350 (1968).

6) M. R. Heble, S. Narayanaswami and M.S. Chadha, Science, 161, 1145 (1968).

7) M. R. Heble, S. Narayanaswami and M.S. Chadha, Phytochemistry, 10, 910 (1971).

8) M. R. Heble, S. Narayanaswami and M.S. Chadha, Phytochemistry, 10, 2393 (1971).

9) P. Khanna, A. Uddin, G. L. Sharma, S. K. Manot and A. K. Rathore, Indian J. Exp. Biol., 14, 694 (1976).
10) P. G. Kadkade and T. R. Madrid, Naturwissenschaften, 64, 147 (1977).

11) J. Ŕérábek, Biol. Plant. (Praha), 9, 285 (1967).

12) D. Vágújfalvi, M. Maróti and P. Tétényi, Phytochemistry, 10, 1389 (1971).

13) T. Murashige and F. Skoog, Physiol. Plantarum, 15, 473 (1962).

14) E. Stahl and U. Kaltenbach, J. Chromatog, 5, 351 (1961). 